Ensino, Saúde e Ambiente - V6 (3), pp. 228-240, dez. 2013

\title{
OFICINA SOBRE ALEITAMENTO MATERNO: UMA EXPERIÊNCIA EXITOSA NUM HOSPITAL REFERÊNCIA EM GESTAÇÃO DE ALTO RISCO
}

\section{WORKSHOP ABOUT BREAST FEEDING: A SUCCESSFUL EXPERIENCE HOSPITAL IN REFERENCE IN HIGH RISK PREGNANCY}

\author{
Técia Maria Santos Carneiro e Cordeiro ${ }^{1}$, Vamberto Ferreira Miranda Filho ${ }^{2}$ \\ ${ }^{1}$ Mestranda do Programa de Pós-Graduação em Saúde Coletiva, Universidade Estadual de Feira de \\ Santana (UEFS), Bahia, Brasil. teciamarya@yahoo.com.br \\ ${ }^{2}$ Docente do Departamento de Educação, Universidade do Estado da Bahia (UNEB)-Campus IV, Bahia, \\ Brasil.
}

\begin{abstract}
RESUMO
Diante da importância da promoção do aleitamento materno por meio da educação em saúde, este estudo tem como objetivo descrever a oficina sobre aleitamento materno para gestantes e puérperas internadas em uma unidade hospitalar referência em gestação de alto risco num município do interior da Bahia. Trata-se de um relato de experiência de caráter descritivo com abordagem qualitativa. A análise dos resultados da oficina deu-se pelo acompanhamento das participantes, para puérperas utilizou-se a análise observacional participante e para as gestantes a análise de enunciação. Os resultados apontaram que todas as puérperas realizaram o posicionamento adequado do neonato na mama, visto que na oficina foi feito à demonstração. Quanto às gestantes, a maioria adquiriu as informações adequadas, por responderem as perguntas corretamente. A oficina foi exitosa por meio de uma educação em saúde grupal proporcionando interação, aprendizagem e trocas de informações e conhecimentos do grupo sobre o aleitamento materno.
\end{abstract}

Palavras-chave: Aleitamento Materno; Gestantes; Promoção da Saúde; Educação em Saúde.

\begin{abstract}
Considering the importance of promotion of breast feeding through health education, this study aims to describe the workshop on breast feeding for pregnant and postpartum women admitted to a hospital reference in high risk pregnancy in a municipality in the interior of Bahia. It is an experience report of descriptive character qualitative approach. The results of the workshop took place for monitoring the participants, to postpartum used the observational analysis participant and for pregnant women to discourse analysis. The results indicate that all the postpartum had the adequate positioning of the neonate at the breast, as was done in the workshop demonstration. As for pregnant women, most acquired appropriate information, for answering the questions correctly. The workshop was successful through a health education group providing interaction, learning and exchange of information and knowledge of the group on breast feeding.
\end{abstract}

Keywords: Breast Feeding; Pregnant Women; Health Promotion; Health Education. 


\section{INTRODUÇÃO}

Uma oficina consiste numa forma de reunir pessoas para discussões, palestras, demonstrações a fim de relacionar a teoria com a prática. No contexto do aleitamento materno auxilia ao desenvolvimento de práticas e técnicas integrativas tanto com puérperas quanto com gestantes, por meio da educação em saúde, a qual propõe um método para produzir conhecimento acerca da saúde às pessoas como proposta estratégica da promoção da saúde.

O aleitamento materno tem sido modelo de atenção para o Ministério da Saúde a ser difundido mundialmente num contexto sociocultural por ser influenciado pelas culturas, crenças, tabus, várias dimensões políticas, tipo e o ambiente hospitalar, permanência no alojamento conjunto e o tipo de parto, além disso, o despreparo dos profissionais de saúde para atuar nesta situação com conceitos e práticas antigas e obsoletas, impedindo a expansão das ações e estratégias (NARCHI et al., 2009; BECK et al., 2012; OLIVEIRA; PAGLIUCA, 2013).

Em 1987 o Ministério da Saúde (MS) estabeleceu o Programa Nacional de Incentivo ao Aleitamento Materno (PNIAM), e logo depois em 1989 a Organização Mundial de Saúde (OMS) em parceria com o Fundo das Nações Unidas para a Infância (UNICEF) elaboraram os dez passos para o sucesso do aleitamento materno com a criação da Iniciativa Hospital Amigo da Criança (IHAC) a fim de favorecer o aleitamento materno e reduzir o desmame precoce e suas consequências sobre a morbimortalidade infantil (MARQUES; MELO, 2008). No ano de 2008 foi instituída a Rede Amamenta Brasil, uma estratégia de promoção, proteção e apoio a prática do aleitamento materno na atenção básica, em 2009 foi estabelecida a Estratégia Nacional para Alimentação Complementar Saudável (ENPACS) para atuar em parceria com a Rede Amamenta Brasil na atenção básica. E em 2012 foi lançada a nova estratégia Amamenta e Alimenta Brasil para reforçar e incentivar a promoção do aleitamento materno e da alimentação saudável para crianças menores de dois anos no âmbito do Sistema Único de Saúde (SUS) (DEPARTAMENTO DA ATENÇÃO BÁSICA, 2012; MINISTÉRIO DA SAÚDE, 2013).

Estas ações e estratégias do Ministério da Saúde beneficiam a criança, a mulher, a família, os profissionais da saúde e o SUS com a redução dos gastos com 
doenças, aumento da prevalência do aleitamento materno e a melhoria dos indicadores de alimentação e nutrição em crianças menores de dois anos, e também o país (Brasil) terá mais cidadãos saudáveis (DEPARTAMENTO DA ATENÇÃO BÁSICA, 2012; MINISTÉRIO DA SAÚDE, 2013). Para o desenvolvimento dessas ações são utilizados critérios metodológicos por meio da educação crítica reflexiva e educação permanente em saúde atreladas a prática pedagógica problematizadora com a participação de todos os atores envolvidos a fim de promover a saúde das pessoas.

A educação em saúde integrou-se às estratégias do Ministério da Saúde, protagonizada por diversos atores da sociedade civil (educadores populares, professores, profissionais de saúde) e essa prática foi afirmada com o direito de participação ativa da comunidade, que proporciona informação, educação sanitária e aperfeiçoa as atitudes indispensáveis para a vida. A educação em saúde com participação popular, chamada educação popular contribui para ampliação do significado dos direitos de cidadania, crescimento e mudança de vida das pessoas. Mobiliza a autonomia individual e coletiva por meio de ações pedagógicas com informações em saúde, permitindo a comunicação, as reivindicações e enunciações para projetar caminhos prazerosos (BRASIL, 2007a). Uma oficina sobre aleitamento materno deve está pautada nestes conceitos explícitos considerando os aspectos socioculturais, conhecimentos prévios e construção de um conhecimento adequado a partir da comunicação e integração popular com objetivo de promover o aleitamento materno.

A promoção da saúde está contida no primeiro nível de prevenção das doenças e deve pautar-se para uma concepção holística de saúde direcionada para a multicausalidade do processo saúde-doença e está relacionada com a autonomia e emancipação por meio de medidas gerais, educativas que objetivam melhorar a resistência e o bem-estar geral dos indivíduos (WESTPHAL, 2009). Observa-se que a promoção do aleitamento materno deve seguir esta concepção de autonomia e construção educativa já que a mulher deve ter o desejo de amamentar, aceitar o filho, a condição de ser mãe e o vínculo afetivo entre o binômio.

A relevância deste estudo deve-se ao risco de doenças e altas taxas de mortalidade infantil pelo não aleitamento materno ou este aleitamento de forma ineficiente e insuficiente por causa da falta de informação das mães, além da escassez ou não informação durante o pré-natal pelos profissionais de saúde da atenção básica. Diante da importância da promoção do aleitamento materno por meio da educação em 
saúde popular, este estudo tem como objetivo descrever a oficina sobre aleitamento materno para gestantes e puérperas internadas em uma unidade hospitalar referência em gestação de alto risco num município do interior da Bahia.

\section{MARCO TEÓRICO}

$\mathrm{O}$ aleitamento materno consiste num alimento rico de fundamental importância para o lactente por oferecer todos os nutrientes, protegê-lo, promover o crescimento e desenvolvimento adequado, sem custos adicionais. Por isto, o enfoque da educação em saúde sobre o aleitamento materno contribui com o contexto da saúde pública por promover benefícios tanto o lactente, a mãe, a família quanto à sociedade.

São inúmeros os benefícios que a prática do aleitamento materno oferece. As vantagens à mãe são: o vínculo afetivo, prevenção de hemorragias no pós-parto, favorece a involução uterina, retorno do peso pré-gestacional mais rápido, reduz os riscos de câncer de ovário e mama e pode prevenir a osteoporose. Para o lactente é um alimento completo em nutrientes, facilita a eliminação de mecônio, diminui o risco de icterícia, protege de infecções e alergias e melhora a resposta à vacinação. Além dessas vantagens o aleitamento também propõe benefícios à família e a sociedade por ser um alimento que não custa nada, é limpo, já vem pronto, economiza o gás de cozinha porque não precisa esquentar, diminui os custos com internações por problemas respiratórios e gastrointestinais e diminui também o absenteísmo dos pais ao trabalho pela criança se manter mais saudável (BRASIL, 2001).

Esta prática de amamentar é assegurada por legislações brasileiras que garantem direitos à mulher, como a licença maternidade por 120 dias regulamentada pela Constituição Federal do Brasil de 1988 no Capítulo I: Artigo XVIII, e em alguns estados e municípios já prevalece a Lei 11.770 de 2008 que garante licença maternidade por 180 dias para todos os servidores públicos. O alojamento conjunto por 24 horas também é regulamentado pela Portaria MS/GM nº 1.016 de 1993. Outro direito é a redução de 1 hora de trabalho diário ou dois descansos de 30 minutos cada para promover o aleitamento materno até completar os seis meses do lactente previsto no Artigo 396 da Consolidação das Leis Trabalhistas e Decreto de Lei n 5.452 de 1943. Essa mulher também não pode ser demitida durante a gestação e até cinco meses após, 
Projeto de Lei $n^{\circ} 7.158$ de 2010. Na prática em sua maior parte esses direitos não são consolidados como previstos nas leis.

No entanto, observa-se a importância do aleitamento materno no contexto familiar, social e cultural, beneficiando a todos por uma prática que não tem custos. Mas, para que este leite seja produzido e ofertado ao lactente de maneira adequada é necessária uma alimentação saudável da lactante, ingestão de bastante líquidos, manter um vínculo afetivo entre o binômio e o cuidado com as mamas expondo-as ao sol pela manhã, não usar sabonetes e pomadas, lavar apenas com água e usar um sutiã adequado, sendo o ideal o sutiã com orifício central para exposição da aréola e mamilo durante a gestação e puerpério. Além do orifício central o sutiã deve ter alças largas para favorecer a sustentação e elevação das mamas evitando estases nas porções inferiores das mamas, ingurgitamento mamário, fissuras nos mamilos a fim de oferecer a pega correta do lactente na aréola.

A educação em saúde é uma forma primordial de promover a saúde das puérperas e gestantes e consequente ao recém-nascido e feto respectivamente através do conhecimento adquirido. O conceito de educação em saúde se sobrepõe ao conceito de promoção à saúde por abordar uma definição mais ampla de um processo que envolve a participação de toda a população no contexto de sua vida cotidiana e não apenas das pessoas sob o risco de adoecer (SCHALL; STRUCHINER, 1999). Partindo deste pressuposto, percebe-se que a educação em saúde através de oficinas como proposta pedagógica vem colaborar para orientações no contexto de uma melhor qualidade de vida e interesses da população na promoção da saúde

No passado a educação em saúde era uma estratégia vertical e ditatorial, na contemporaneidade é construída junto aos atores sociais respeitando suas culturas, crenças, valores e troca de saberes (BRASIL, 2007a). A educação em saúde deve ser uma proposta dos profissionais e instituições de saúde para apoiar o aleitamento materno através da implementação de normas e rotinas, incentivar a formação de grupos de gestantes e lactantes, organizar oficinas integrativas, acompanhar e avaliar a técnica do aleitamento materno quando em contato com o binômio. Observa-se um déficit neste aspecto por deparar-se com baixo índice do aleitamento materno exclusivo e alto do misto que é o aleitamento acompanhado de outros alimentos como chás, sucos, água, sendo que o leite materno sozinho já fornece todos os nutrientes necessários para o lactente, assim como, sacia a sua sede. 
Através de uma pesquisa realizada pelo Ministério da Saúde sobre a prevalência do aleitamento materno nas capitais brasileiras e Distrito Federal, a prevalência do aleitamento materno exclusivo nas capitais brasileiras foi de apenas $41 \%$, indicador heterogêneo nas diversas regiões, sendo que a pior situação desta prática é a região Nordeste com $37 \%$ e a de melhor situação é a região Norte com $45,9 \%$ (BRASIL, 2009). Assim, percebe-se a necessidade de sensibilização da promoção do aleitamento materno, iniciando a partir do pré-natal para assegurar a autonomia as gestantes dos benefícios e poder da amamentação. Também é necessário sensibilização e atitudes dos profissionais de saúde em colaborar com essa prática tão eficaz.

A promoção da saúde no processo de educar em saúde supõe a criação de espaços saudáveis, como a saúde é produzida socialmente então é desejável que as pessoas participem da reflexão sobre os aspectos que levam a ter uma saúde (WESTPHAL, 2009). Por isso, a relevância de uma oficina como proposta de educação em saúde para as gestantes e puérperas participarem e aprenderem através de discussões e trocas de comunicações que possibilitará melhores condições de vida.

\section{METODOLOGIA}

Trata-se de um relato de experiência de caráter descritivo desenvolvido através de uma oficina em uma unidade materno infantil de um hospital de grande porte, referência em gestação de alto risco num município do interior da Bahia. Segundo Gil (2002) o estudo descritivo tem como objetivo primordial descrever as características de um determinado fenômeno, população, utilizando técnicas padronizadas de coletas de dados como questionário e observação sistemática. A abordagem utilizada foi a qualitativa com a descrição dos fatos, discussões com a literatura e apresentação dos dados.

A oficina deu-se através da necessidade de promover à educação em saúde as gestantes e puérperas quanto ao aleitamento materno, diagnosticado por meio de um Planejamento Estratégico Situacional (PES) realizado por uma acadêmica de enfermagem no último estágio supervisionado II. O lócus do estudo é referência em gestação de alto risco para a regional de saúde do município e presta assistência por meio do Sistema Único de Saúde (SUS) a gestantes e puérperas em situação de risco para o binômio. 
Na elaboração da oficina consideraram-se aspectos teóricos referentes ao aleitamento materno, manuais do Ministério da Saúde, artigos e a educação em saúde popular que permite uma estratégia metodológica participante. Para realização foi feito um convite verbal as gestantes e puérperas internadas em todas as enfermarias da unidade. A oficina foi ministrada por uma acadêmica de enfermagem por meio da exposição oral com técnicas de aprendizagem interagindo com o público alvo estimulando a participação, a comunicação, a autonomia e a expressão de opiniões, contribuindo para o aprendizado em grupo com trocas de conhecimentos, experiências, esclarecimento de dúvidas e desenvolvimento das práticas orientadas. As metodologias participantes estão associadas à discussão e autonomia dos participantes, a reflexão, o diálogo e a construção compartilhada de conhecimentos que representam ferramentas e propiciam o encontro entre cultura popular e científica e remete a importância da escuta e fala dos atores que se põem em relação (BRASIL, 2007a; ROZEMBERG, 2009).

Houve quatorze participantes na oficina, sendo seis gestantes e oito puérperas com idades entre 22 - 39 anos, as gestantes do $6^{\circ}$ ao $9^{\circ}$ mês de gestação, maioria casada/união estável, diferentes níveis de escolaridade e a maior parte com diagnóstico de Doença Hipertensiva Específica da Gestação (DHEG). Foram abordadas as principais situações que envolvem a prática do aleitamento materno, como cuidados com as mamas, a pega correta da mama pelo neonato, as posições adequadas para esta pega correta, as indicações e contra-indicações do aleitamento materno, os benefícios, o uso adequado do sutiã e sua importância considerando os aspectos socioculturais das participantes, o planejamento da gestação e o desejo de amamentar.

Observa-se a relevância de uma oficina como modelo estratégico para o aprendizado e trocas de experiências em grupo promovendo o conhecimento adequado de um grupo alvo para uma determinada questão problematizadora na abordagem metodológica da prática dialógica de Paulo Freire que se refere à capacidade de ouvir o outro buscando perceber as diferenças, singularidades e trabalhando-as (BRASIL, 2007a).

Durante a oficina utilizou-se a demonstração da técnica da amamentação abordando a pega correta e posicionamento do neonato na mama, quando oferecer a mama e quando terminar a mamada conforme preconizado pelo Ministério da Saúde (BRASIL, 2007b) com o uso de recursos materiais como: protótipo de mamas, bebê boneco, panfletos, cartazes e sutiãs. Também foi abordado o uso adequado do sutiã 
mostrando seus detalhes e importância. A linguagem utilizada tanto na troca de conhecimentos quanto nos materiais educativos foi clara e objetiva para favorecer o entendimento da população alvo.

A análise dos resultados da oficina deu-se pelo acompanhamento das participantes por dois dias após a realização. Para as puérperas utilizou-se a análise observacional participante da técnica da amamentação, que segundo Minayo (2010) consiste num processo pelo qual mantém a presença do observador numa determinada situação para realizar uma investigação científica. E para as gestantes utilizou-se a análise da enunciação numa concepção de comunicação e do discurso como palavra em ato, que de acordo com Minayo (2010) é um produto inacabado, um momento de criação de significados que comportam de contradições, incoerências e imperfeições a fim de analisar o conhecimento por meio de uma entrevista aberta sobre os assuntos abordados na oficina, iniciando com os seguintes questionamentos: Quais os benefícios do aleitamento materno? Como posicionar o bebê de forma adequada? De que forma você percebe que o bebê está sugando corretamente?. Esta análise foi feita a fim de obter resultados com a implementação da oficina em uma unidade hospitalar em que esta estratégia não faz parte da rotina.

Foram respeitados os aspectos éticos de acordo a Resolução 466/12 pelos resultados não ter se referido a nenhum indivíduo, e nem tampouco ter causado prejuízos a instituição envolvida. Este tipo de estudo se trata de um relato de uma experiência vivenciado pela autora, o que exime a aprovação pelo Comitê de Ética em Pesquisa.

\section{RESULTADOS E DISCUSSÃO}

Esta oficina proporcionou bons resultados na unidade por sair da rotina, estimular a integração e participação das gestantes e puérperas favorecendo o acesso a informações sobre o aleitamento materno e todo o seu contexto. $\mathrm{O}$ aleitamento materno tem forte papel de proteção na morbimortalidade infantil, a sua falta influência um grande número de doenças principalmente infecciosas, sendo importante para a sobrevivência das crianças pobres em países em desenvolvimento como é o caso do Brasil, as quais estão em risco constante de adoecerem devido à complexa associação da 
má nutrição, falta de saneamento, infecções e falta de alimentação nutritiva (FRAIFER; SANTO, 2011).

Durante a oficina foi observado o envolvimento e interesse das gestantes e puérperas na troca de conhecimentos, assim como a disponibilidade em realizar a demonstração das posições adequadas com o neonato/boneco para o aleitamento materno. Foi observado também que fatores socioeconômicos, culturais, faixa etária, aceitação da gravidez desejada ou indesejada, situação de risco da gestação influenciaram nos questionamentos e participação. A maioria das participantes primigestas, primíparas e multíparas tinham dificuldades de amamentar. Isso foi observado também no estudo de Marques e Melo (2008) numa Maternidade em Maceió, onde 20 a $60 \%$ dos binômios apresentaram alguma dificuldade com o início da amamentação, diagnosticado a necessidade de orientação das mães para sanar estas dificuldades o mais breve possível.

$\mathrm{Na}$ oficina foram esclarecidas as dúvidas e questionamentos oportunizando as gestantes e puérperas a falar de seus anseios, medos, superações, constituindo um momento de integração. Uma das puérperas que realizou a demonstração da técnica da amamentação relatou: “minha maior dificuldade é ter o mamilo plano”. Sendo desta forma aproveitado o momento para explicar como estimular a tração do mamilo plano para facilitar o neonato na pega correta utilizando os exercícios de protração do mamilo com a tração de seringa de $20 \mathrm{ml}$ ou também conhecido como técnica da seringa invertida, a qual deve cortar o bico da seringa de $20 \mathrm{ml}$, colocar o êmbolo ao contrário e encaixar no mamilo puxando de forma suave para promover a tração, é indicado a realizar várias vezes ao dia e sempre antes de amamentar (UNICEF, 2008).

Participaram da oficina quatorze gestantes e puérperas de vinte internadas e convidadas, o que corresponde a $70 \%$ considerado um índice positivo pela situação de alto risco dos binômios e gestantes. Nove das participantes ganharam sutiã com alças largas e orifício central no final da oficina por meio de um sorteio, as participantes também receberam materiais educativos sobre aleitamento materno, a pega correta do neonato na mama, cuidados com a mamãe e com o bebê, e também sobre doação de leite humano.

Com o acompanhamento e avaliação por dois dias das participantes após a oficina foi observado que todas as puérperas realizaram o posicionamento adequado do neonato na mama em consequência favorecendo a pega correta, visto que na oficina foi 
feito a demonstração e trocas de experiências e conhecimentos. Quanto às gestantes, a maioria adquiriu as informações adequadas, por responderem as perguntas corretamente de acordo às estratégias metodológicas da oficina. Observa-se a efetividade da oficina por meio de uma educação em saúde grupal que proporcionou uma interação e aprendizagem da maior parte do grupo sobre o aleitamento materno, ou seja, um efeito ou impacto real de uma ação de saúde sobre a saúde da população (VASCONCELOS; PACHES, 2009).

Silva e Souza (2005) em seu estudo sobre a prevalência do aleitamento materno na cidade de Lins encontrou uma semelhança em comparação aos centros de saúde públicos e privados, justificado pelo trabalho intenso de promoção do aleitamento materno, principalmente em grupos populacionais menos privilegiados. Esse parâmetro confirma que a promoção do aleitamento materno constitui em uma das formas mais eficazes em relação a custos e redução da morbimortalidade infantil e para isso é necessário a união da sociedade, governos e instituições de saúde.

Observou-se também uma fragilidade por parte dos profissionais de saúde, em especial os enfermeiros, da unidade hospitalar do presente estudo e da atenção básica onde as participantes realizavam o pré-natal, em promover o aleitamento materno por meio de ações e estratégias de conhecimentos, participação e autonomia das mulheres. As informações passadas eram obsoletas, antigas e referiam-se mais a técnica e não a relevância da prática de amamentar para toda a sociedade. Num estudo realizado com profissionais de enfermagem da atenção básica de Uberaba permitiu sensibilizar estes profissionais e gestores quanto à necessidade da educação permanente em aleitamento materno para efetivar as atividades de promoção desta prática social, o aumento da prevalência e duração. Já que os profissionais tinham fragilidade de conhecimento metodológico referente à teoria-prática do aleitamento materno (MACHADO et al., 2012).

$\mathrm{O}$ enfermeiro como membro de uma equipe multiprofissional desempenha funções de educador e promotor da saúde através de tecnologias e competências da arte do cuidar (OLIVEIRA; PLAGLIUCA, 2013). Sabe-se das responsabilidades de um enfermeiro da atenção básica e do nível terciário, entretanto, esse profissional é um multiplicador de conhecimentos e deve está desenvolvendo na sua rotina educação em saúde com grupos específicos da população ao considerar a participação popular com trocas de experiências, conhecimentos e informações. Para reduzir as taxas de 
morbimortalidade infantil, aumentar a prevalência do aleitamento materno, contribuir para uma alimentação saudável, e também para favorecer a saúde da mulher (lactante) e tornar cidadãos mais saudáveis é necessário a elaboração de estratégias e ações em todas as unidades de saúde para promover o aleitamento materno.

\section{CONCLUSÃO}

A oficina obteve bons resultados quanto ao aprendizado, à troca de experiências, informações e conhecimentos acerca do aleitamento materno proporcionando uma boa pega dos neonatos na mama, assim como o conhecimento acerca da promoção do aleitamento materno e questionamentos pelas gestantes e puérperas internadas na unidade. A educação em saúde mostrou-se fundamental para se alcançar a promoção da saúde dos indivíduos, e em razão de grupos, a oficina mostrouse capaz de esclarecer questionamentos, práticas, conhecimentos e informações adequadas.

Observa-se que seria primordial uma educação em saúde com enfoque maior no aleitamento materno na atenção básica desde a primeira consulta de pré-natal e também seria necessária uma sensibilização dos profissionais de saúde da atenção básica e dos hospitais, em especial o enfermeiro, para promover esta educação em saúde, que constitui um papel na função de cada profissional. A educação em saúde popular é uma estratégia que corrobora para proporcionar um conhecimento adequado da importância do aleitamento materno para todas as mulheres, crianças e a sociedade brasileira.

A experiência com esta oficina foi exitosa para aprimorar os conhecimentos técnicos, científicos e metodológicos a cerca da educação em saúde e função do profissional de saúde, enfermeiro, como educador. Também foi relevante a troca de conhecimentos, experiências e informações com as puérperas e gestantes promovendo assim um retorno positivo para a proposta de intervenção.

As limitações foram acerca da confiança estabelecida entre ambas as partes envolvidas na oficina e na avaliação do conhecimento e técnica, mas, foram superadas com humildade e clareza dos benefícios promovidos pelo aleitamento materno. Contudo, esperamos que este estudo sensibilize e estimule os profissionais de saúde e 
enfermeiros para atuarem no âmbito da educação para promoção da saúde dos brasileiros corroborando com cidadãos mais saudáveis.

\section{REFERÊNCIAS}

BECK A. M. O. et al. Influência do ambiente hospitalar nos aspectos relacionados ao aleitamento materno. Revista da Sociedade Brasileira de Fonoaudiologia, v. 17, n. 4, p. 464-8, 2012.

BRASIL. Secretaria de Políticas Públicas, Área Técnica em Saúde da Mulher. Parto, Aborto e Puérperio: assistência humanizada à mulher. Brasília: Ministério da Saúde, 2001 .

BRASIL. Secretaria de Gestão Estratégica e Participativa. Caderno de Educação Popular em Saúde. Brasília: Ministério da Saúde, 2007a. 160 p. (Série B de textos básicos de saúde).

BRASIL. Secretaria de Atenção à Saúde. Promovendo o Aleitamento Materno. 2. ed. revisada. Brasília: Ministério da Saúde, 2007b.

BRASIL. Secretaria de Atenção à Saúde, Departamento de Ações Programáticas e Estratégicas. II Pesquisa de Prevalência de Aleitamento Materno nas Capitais Brasileiras e Distrito Federal. Brasília: Ministério da Saúde, 2009.

BRASIL. Constituição da República Federativa do Brasil. Brasília: Senado Federal; 1998.

BRASIL. Lei $\mathbf{n}^{\mathbf{0}} \mathbf{1 1 . 7 7 0}$ de 09 de setembro de 2008. Brasília, 2008.

BRASIL. Portaria MS/GM no 1.016 de 26 de agosto de 1993. Brasília, 1993.

BRASIL. Decreto de Lei no 5.452 de 1 de maio de 1943. Brasília, 1943.

BRASIL. Lei no 7.158 de 15 de abril de 2010. Brasília, 2010.

DEPARTAMENTO DE ATENÇÃO BÁSICA (DAB). Lançada nova estratégia Amamenta e Alimenta Brasil [internet]. 29 abr. 2012. Disponível:

http://dab.saude.gov/noticia/noticia_ret_detalhe.php?cod+1528. Acesso: 08 abr. 2013.

FRAIFER V. S. S.; SANTO E. E. A importância da exclusividade do aleitamento materno nos primeiros seis meses de vida. Diálogos e Ciências, v. 26, p. 1-10, jun. 2011.

GIL A. C. Como Elaborar Projetos de Pesquisa. 4. ed. São Paulo: Atlas, 2002.

MACHADO M. O. F. et al. Aleitamento materno: conhecimento e prática. Revista da Escola de Enfermagem da USP, v. 46, n. 4, p. 809-15, 2012. 
MARQUES M. C. S.; MELO A. M. Amamentação no alojamento conjunto. Revista CEFAC, v. 10, n. 2, p. 261-71, abr.-jun. 2008.

MINAYO M. C. S. O Desafio do Conhecimento: Pesquisa Qualitativa em Saúde. 12. ed. São Paulo: HUCITEC, 2010.

MINISTÉRIO DA SAÚDE. Rede Amamenta Brasil [internet]. Disponível: http://portal.saude.gov.br/portal/saude/cidadao/visualizar_texto.cfm?idtxt.30133. Acesso: 08 abr. 2013.

NARCHI N. Z. et al. Variáveis que influenciam a manutenção do aleitamento materno exclusivo. Revista da Escola de Enfermagem da USP, v. 43, n. 1, p. 87-94, 2009.

OLIVEIRA P. M. P.; PAGLIUCA L. M. F. Avaliação de tecnologia educativa na modalidade literatura de cordel sobre amamentação. Revista da Escola de Enfermagem da USP, v. 47, n. 1, p. 205-12, 2013.

ROZEMBERG B. Comunicação e participação em saúde. In: CAMPOS G. W. S. et al. Tratado de Saúde coletiva. 2. ed. São Paulo: HUCITEC. Rio de Janeiro: FIOCRUZ, 2009. p. 741-766.

SCHALL V. T.; STRUCHINER M. Educação em Saúde: novas perspectivas. Cadernos de Saúde Pública, v. 15, supl. 2, p. S4-S6, 1999.

SILVA A. P.; SOUZA N. Prevalência do aleitamento materno. Revista de Nutrição, v. 18, n. 3, p. 301-10, maio-jun. 2005.

UNICEF. Comitê Português para a Unicef. Comissão Nacional, Iniciativa hospitais amigos dos bebês. Manual de Aleitamento Materno. Edição Revista, 2008.

VASCONCELOS C. M.; PACHES D. F. O Sistema Único de Saúde. In: CAMPOS G. W. S. et al. Tratado de Saúde coletiva. 2. ed. São Paulo: HUCITEC. Rio de Janeiro: FIOCRUZ, 2009. p. 531-562.

WESTPHAL M. F. Promoção da Saúde e Prevenção de Doenças. In: CAMPOS G. W. S. et al. Tratado de Saúde coletiva. 2. ed. São Paulo: HUCITEC. Rio de Janeiro: FIOCRUZ, 2009. p. 635-668. 